\title{
The Clinical Effectiveness and Cost-Effectiveness of Rituximab Versus Natalizumab in Patients With Relapsing Remitting Multiple Sclerosis
}

\section{Mehdi Rezaee}

Kerman University of Medical Sciences

Mohammad Hossein Morowvat

Shiraz University of Medical Sciences

Maryam Poursadeghfard

Shiraz University of Medical Sciences

Armin Radgoudarzi

Shiraz University of Medical Sciences

Khosro Keshavarz ( $\nabla$ khkeshavarz2007@gmail.com )

Shiraz University of Medical Sciences

\section{Research Article}

Keywords: Multiple Sclerosis, Natalizumab, Rituximab, QALY

Posted Date: September 27th, 2021

DOI: https://doi.org/10.21203/rs.3.rs-898078/v1

License: (9) This work is licensed under a Creative Commons Attribution 4.0 International License. Read Full License 


\section{Abstract}

Introduction: Multiple sclerosis (MS) is an inflammatory disease in which the myelin sheaths of the nerve cells in the brain and spinal cord, which are responsible for communication, are destroyed and cause physical signs and symptoms. According to studies, anti-CD20 monoclonal antibodies have significant results in the treatment of this disease. Thus, the aim of the present study was to determine the effectiveness and cost-effectiveness of Rituximab against Natalizumab in the patients with MS in southern Iran in 2020.

Methods: This is an economic evaluation including cost-effectiveness analysis in which the Markov model with a lifetime horizon was used. The study sample consisted of 120 patients randomly selected from among those referred to the MS Association and the Special Diseases Unit of Shiraz University of Medical Sciences. In this study, the costs were collected from a societal perspective, and the outcomes were obtained in the form of Quality Adjusted Life Years (QALY) and the mean recurrence rate. The TreeAge pro 2020 and Excel 2016 software were used for data analysis.

Results: The comparative study of Rituximab and Natalizumab showed that the patients receiving Rituximab had lower costs (\$58307.931 vs. \$354174.85) and more QALYs (7.77 vs. 7.65). In addition, the incidence of relapse by Rituximab was lower compared to Natalizumab (1.15 vs. 2.57). The probabilistic one-way sensitivity analysis showed the robustness of the results. The scatter plots also showed that Rituximab was more cost-effective for the patients in $100 \%$ of the simulations for the threshold of $>\$ 37,641$.

Discussion and Conclusion: According to the results of this study, Rituximab had higher cost-utility and cost-effectiveness than Natalizumab. Therefore, it could be a priority for MS patients compared to Natalizumab because it reduced treatment costs and increased effectiveness.

\section{Background}

Multiple sclerosis (MS) is an inflammatory disease in which the myelin sheaths of the nerve cells in the brain and spinal cord are damaged. The damage can impair the ability of some parts of the nervous system responsible for communication and cause many physical signs and symptoms $(1,2)$. Although the cause of the disease is unknown, its main mechanism is damage by the immune system or disruption of myelin sheath-producing cells (2). The number of MS patients has increased from 2.3 million in 2013 to 2.8 million in 2020; however, the incidence rates vary markedly in different parts of the world and in different communities (3). The disease usually occurs at the age of $20-50$ and is about 3 times more common among women than men (4). The prevalence of multiple sclerosis in Iran has also increased significantly in recent years, reaching from 73.7 per 100,000 in 2006 to 137.6 per 100,000 in 2018 (5). According to the studies carried out from 2011 to 2020 in different provinces, the prevalence of the disease in Iran ranged from 27.7 per 100,000 in East Azerbaijan to 148.06 per 100,000 in Tehran (6-12). 
In addition, a meta-analysis research carried out in 2020 indicated that the annual prevalence of multiple sclerosis had increased by $2.3 \%$ during $1985-2018$ (13).

According to studies, multiple sclerosis has a significant negative effect on patients' quality of life (14). The average life expectancy of the patients is 40 years from the onset of the disease, which is 5 to 10 years less than the average life expectancy of non-infected people. About $60 \%$ of MS patients reach the age of 70 (15). Furthermore, studying the patients with reduced disability DMT showed that about $90 \%$ of the total cost of the patients with mild to moderate disability was associated to drugs, and it was found out that the costs of drugs (except DMT) and non-medical sources were higher for the patients with a more severe disease. The increased disability also had a significant effect on health-related quality of life and the fatigue in daily life (16).

Studies show that multiple sclerosis imposes a significant economic burden on patients and societies. The findings of a study indicated that the cost of annual health care per MS patient increased from $\$$ 45,471 in 2011 to $\$ 62,500$ in 2015 , representing an average annual growth of $8.3 \%$. In addition, the annual cost of purchasing medication for each MS patient increased from $\$ 26,772$ to $\$ 43,606$, with an average annual growth rate of $13.0 \%$ (17). A study conducted in Spain also found that the total cost of MS was $€ 1,395$ million per year, with an average annual cost of $€ 30,050$ per patient. In addition to the costs, the disease had a significant effect on patients' quality of life, and it was estimated that sclerosis imposes would cause a loss of 13,000 QALYs annually. In general, MS had a great economic impact on the Spanish society and a significant effect on the patients' quality of life (18).

There is currently no definitive cure for MS, but various drugs are being used to better control the disease and better adapt the patients to the conditions, amongst which are interferon beta and Glatiramer acetate, oral drugs (Dimethyl fumarate, Teriflunomide and Fingolimod) as well as Natalizumab and Alemtuzumab (19). Monoclonal antibodies are currently very popular with specialists. They act against the CD20 protein like Rituximab, Ocrelizumab, and Ofatumumab that have all shown positive results and are being studied as potential drugs (20). Rituximab is a drug used to treat some types of autoimmune diseases and cancers. It is a chimeric monoclonal antibody against the CD20 protein that is commonly found on the surface of B-lymphocytes. Rituximab binds to CD20 and causes cell death. Relatively common complications that often occur 2 hours after starting the injection include skin rash, itching, low blood pressure, and dyspnea (21).

In general, considering the increased number of multiple sclerosis patients as well as the increasing costs of the disease imposed on the patients and societies (22), and since the researchers found no study conducted to evaluate the cost-effectiveness of Rituximab and Natalizumab, the present research aimed to determine the effectiveness and cost-effectiveness of these two drugs in the patients with relapsing remitting multiple sclerosis in Fars province in 2020 in order to identify the most cost-effective one for the patients with MS and to help managers, policy makers, and specialists prescribe better drugs and use the limited resources properly. 


\section{Methods}

\section{Overview and Model Structure:}

This is a full economic evaluation of cost-effectiveness analysis type conducted on the patients using Natalizumab and Rituximab who referred to the MS Association and the Special Diseases Unit of Shiraz University of Medical Sciences in 2020. According to the results of the pilot study and considering $a=5 \%$, $S D=1.01$, and $d=0.25$, the sample size was determined to be 60 in each group. The patients were selected through the random sampling method and entered the study. The inclusion criteria were the use of the mentioned drugs for at least one year and the willingness to participate in the research.

Due to the chronic and relapsing nature of multiple sclerosis, the Markov model was used in this study. Figure 1 indicates a schematic diagram of the Markov model for the disease. The time horizon in this study was the lifespan and the interval of the annual Markov cycles. For each one-year cycle in the model, the patients remained in their current states or were transferred to other ones, and any patient might experience relapse or death $(23,24)$. All the probabilities of transition to other states, Annualized Relapse Rate, and the probability of death in each Expanded Disability Status Scale (EDSS) were extracted based on previously published studies and were presented in Table 11 (25-28). It should be noted that some clinical trial data were reported as rates. They were first converted to transition probabilities using the following formula, and the transition probabilities were then entered the model (29).

$P=1-\exp (-r t)$

where $\mathrm{p}$ is wanted transition probability and $\mathrm{r}$ is the overall rate over the time of $\mathrm{t}$.

Since the time horizon was over one year, the cost data and the outcomes of the model were discounted based on the discount rates of $5.8 \%(30)$ and $3 \%(31)$, respectively.

Table 1: Transmission probabilities and annual relapse rates in patients with relapsing remitting multiple sclerosis:

\begin{tabular}{|c|c|c|c|c|c|c|c|}
\hline EDSS From\To & $0-2.5$ & $3-5.5$ & $6-7.5$ & 8-9.5 & source & Death & Source \\
\hline $0-2.5$ & 82.567 & 15.93 & 1.47 & 0.033 & \multirow[t]{4}{*}{$(25,32,33)$} & 1.343 & \multirow[t]{4}{*}{ (28) } \\
\hline 3-5.5 & 10.067 & 59.73 & 28.8 & 1.4 & & 1.718 & \\
\hline $6-7.5$ & 0.3 & 5.5 & 81.95 & 12.25 & & 2.685 & \\
\hline 8-9.5 & 0 & 0.1 & 4.15 & 95.75 & & 5.450 & \\
\hline \multicolumn{2}{|c|}{ Annualized Relapse Rate } & \multicolumn{3}{|l|}{ Mean } & \multicolumn{3}{|l|}{ Source } \\
\hline \multicolumn{2}{|l|}{ Rituximab } & \multicolumn{3}{|c|}{$0.11+0.26[-0.15-0.37]$} & \multicolumn{3}{|l|}{ (27) } \\
\hline \multicolumn{2}{|l|}{ Natalizumab } & \multicolumn{3}{|c|}{$0.308[0.225-0.42]$} & \multicolumn{3}{|l|}{$(26)$} \\
\hline
\end{tabular}


The outcomes entered this model included QALYs and the costs of any health condition and any treatment strategy. Utility scores were extracted using the Euro Quality-5 Dimension (EQ-5D) questionnaire, and the health outcomes were valued based on quality-adjusted life years (QALY) (34). To measure the utility scores, face-to-face interviews or telephone calls with 120 MS patients were done in 2020. The interviews were conducted with the outpatients referred to the hospitals and clinics affiliated to Shiraz University of Medical Sciences. It is worth noting that the EQ-5D questionnaire is a standard tool used to measure health outcomes and includes 5 questions that measure mobility, self-care, usual activities, pain / discomfort, and anxiety / depression. Respondents can score each aspect from 0 to 1 , and higher scores mean better utility. The questionnaire was introduced by the EuroQol group in 1990 (https://euroqol.org/). The MS patients who were willing to participate in the present study were interviewed accordingly. Once the EQ-5D questionnaire was completed, its 5-digit codes were changed into numerical utility by considering the values of Iran determined by Goodarzi et al. (35) using the time trade-off method (TTO).

The community perspective was also used to extract the costs. The relevant costs from a community perspective included Direct Medical Costs (DMC), Direct Non-Medical Costs (DNMC), and Indirect Costs (IC). The DMC of each drug was collected retrospectively from March 21, 2019, to March 20, 2020, using a researcher-made checklist and by referring to specialists' offices physicians and the MS Association of Fars Province. The DMC included the costs of visits, purchase of medicine, MRI, tests, hospitalization, and physiotherapy. The DNMC included the costs of traveling to other cities and accommodation as well as the meals consumed by the patient and his/ her family, and the nursing home care expenses determined by asking the patients. The human capital approach was used for IC calculation (36-38).

In this study, all the expenses were converted into dollars Purchasing Power Parity (PPP) using the exchange rate of each PPP dollar equal to 22075 Rials in 2019 (39).

\section{Effectiveness}

The mean relapse rate was used to measure effectiveness. To this end, the total number of relapses of all patients was calculated and divided by the total number of years of drug use to obtain the annual relapse rate of the patients. The obtained value was then divided by the number of patients using each drug in order to obtain the mean relapse rate of each drug $(40,41)$.

\section{Determining the Incremental Cost-Effectiveness Ratio}

After the calculation of the costs and utilities in the previous stages, the incremental cost-utility was calculated using the following formula. To make the final decision on the cost-effectiveness of each intended drug, the ICER level was compared with the threshold. 


\section{ICER $=\frac{\text { Costs of Natalizumab }- \text { Costs of Rituximab }}{\text { Outcomes of Natalizumab-Outcomes of Rituximab }}$}

Due to the lack of an explicit threshold for Willingness To Pay (WTP) in Iran, the WHO's proposal for developing countries was used, i.e. the willingness to pay per QALY was one to three times the per capita Gross Domestic Product (GDP) (42). In Iran, GDP was \$12,547 in 2019 (43) based on which the threshold for willingness to pay was $\$ 37,641$ (3* GDP). The Excel 2016 and TreeAge Pro 2020 software were also used for data analysis.

\section{Sensitivity Analysis}

The researchers used the one-way sensitivity analysis and Probabilistic Sensitivity Analysis (PSA) to investigate the effects of parameter uncertainty on the results. In order to perform the one-way sensitivity analysis, some key parameters such as cost and utility were changed by $20 \%$ for each drug strategy and the results were presented in the form of a Tornado Diagram. In addition, since the utility and cost variables in the present study were measurable and probabilistic, PSA was performed and they were considered as distributions, so that beta distribution ( $($ ) was used to determine the distribution of utility values (ranged from 0 to 1 ) and gamma distribution was used to determine the cost distribution. Accordingly, Second-order Monte Carlo simulation was performed using 5000 trials. The PSA results are presented using the cost-effectiveness acceptability curve and incremental cost-effectiveness scatter plot. Cost-effectiveness acceptability curve is one of the best curves for planning and policy-making that can help health policy makers and planners identify the probability of cost-effectiveness of each intervention in exchange for different WTPs. On the other hand, scatter plots provide more detailed information in individual comparisons. The plots actually indicate the percentage of the points in the acceptance area, i.e. below the threshold (44).

\section{Results}

The findings of the present research showed that most of the patients were female $(74.17 \%)$ and housewives (52.50\%), and all of the patients had an insurance coverage. In addition, the mean ages of the patients treated with Natalizumab and Rituximab were $33.4 \pm 7.27$ and $34.92 \pm 5.94$ years, respectively.

Tables 2 and 3 show the mean cost, utility, and relapse in the multiple sclerosis patients using Natalizumab and Rituximab. According to Table 2, the highest mean DMC and DNMC rates were associated to the patients taking Natalizumab (\$34,912.80 and $\$ 665.70$, respectively). Also, the cost of purchasing the main drug was the highest type of DMC in Natalizumab and Rituximab groups ( $\$$ $32,942.24$ for Natalizumab and \$2,038.51 for Rituximab). Furthermore, travel expenses and income lost of the outpatients accounted for the highest DNMCs and ICs in both groups ( $\$ 441.72$ and $\$ 282.83$ for Natalizumab, and \$ 27.94 and \$ 254.72 for Rituximab, respectively). 
Table 2

The means of costs in RRMS patients using Natalizumab and Rituximab

\begin{tabular}{|cllll|}
\hline Costs & \multicolumn{3}{l}{ Natalizumab } & \multicolumn{2}{l}{ Rituximab } \\
\cline { 2 - 5 } & USD & Percentage & USD & Percentage \\
\hline Direct Medical Costs & & & & \\
\hline Physicians' Visits & 258.00 & 0.74 & 89.90 & 1.82 \\
\hline Main Medicines & $32,942.24$ & 94.36 & $2,038.51$ & 41.33 \\
\hline Supplementary Medicines & 695.69 & 1.99 & 421.64 & 8.55 \\
\hline Laboratory Tests & 267.18 & 0.77 & 220.63 & 4.47 \\
\hline MRls & 508.09 & 1.46 & $1,457.97$ & 29.56 \\
\hline Physiotherapy \& Other Services & 0.00 & 0.00 & 647.27 & 13.12 \\
\hline Costs & & & & \\
\hline Hospitalization \& Surgeries & 241.60 & 0.69 & 56.04 & 1.14 \\
\hline Total & $34,912.80$ & 96.82 & $4,931.96$ & 91.34 \\
\hline Direct Non-Medical Costs & & & & \\
\hline Transportation & & & & \\
\hline Accommodation & 441.72 & 66.35 & 27.94 & 67.94 \\
\hline Meals & 53.14 & 7.98 & 0.00 & 0.00 \\
\hline Purchasing Auxiliary Tools & 117.70 & 17.68 & 13.18 & 32.06 \\
\hline Total & 665.70 & 1.85 & 41.12 & 0.76 \\
\hline Indirect Costs & 53.14 & 7.98 & 0.00 & 0.00 \\
\hline Income Lost due to Outpatient Visits & 282.83 & 58.97 & 254.72 & 59.76 \\
\hline Income Lost due to Hospitalization & 79.27 & 16.53 & 64.40 & 15.11 \\
\hline Patient's Family Costs & 117.48 & 24.50 & 107.08 & 25.13 \\
\hline Total & 479.58 & 1.33 & 426.20 & 7.89 \\
\hline Total Costs & 100.00 & $5,399.28$ & 100.00 \\
\hline
\end{tabular}

As shown in Table 3, the highest utility score obtained from the EQ-5D questionnaire was that of the MS patients using Rituximab and with the EDSS of 0.5-2 (0.833 \pm 0.125$)$. The lowest mean relapse was that of the patients using Rituximab with the EDSS of 0.5-2 (0.313 \pm 0.528$)$. 
Table 3

The means of utility scores and relapses avoided rates in RRMS patients using Natalizumab and

Rituximab

\begin{tabular}{|lllll|}
\hline Parameters & \multicolumn{2}{c}{ Natalizumab } & \multicolumn{2}{c|}{ Rituximab } \\
\hline & Mean & SD & Mean & SD \\
\hline Utility Scores & & & & \\
\hline EDSS 0.0-2.5 & 0.754 & 0.186 & 0.833 & 0.125 \\
\hline EDSS 3.0-5.5 & 0.530 & 0.120 & 0.621 & 0.097 \\
\hline Relapse Rates & & & & \\
\hline EDSS 0.0-2.5 & 1.024 & 1.506 & 0.313 & 0.528 \\
\hline EDSS 3.0-5.5 & 1.667 & 1.782 & 1.727 & 0.905 \\
\hline
\end{tabular}

As presented in Fig. 2 and Table 4, the results of the cost-utility analysis using the Markov model suggested that the mean cost was $\$ 58,307,931$ in the Rituximab arm and the QALY was 7.77 as well. However, the mean predicted cost in the Natalizumab arm was $\$ 354,174.85$ and the obtained QALY was $\$ 7.65$.

Table 4

The base-case analysis results (the lifetime analysis)

\begin{tabular}{|lllllll|}
\hline Strategy & $\begin{array}{l}\text { cost } \\
\text { (PPPS) }\end{array}$ & QALY & $\begin{array}{l}\text { Incremental } \\
\text { Cost }\end{array}$ & $\begin{array}{l}\text { Incremental } \\
\text { QALY }\end{array}$ & $\begin{array}{l}\text { ICUR } \\
\text { (Incremental } \\
\text { cost per } \\
\text { QALY } \\
\text { Gained) } \\
\text { PPPS }\end{array}$ \\
\hline $\begin{array}{l}\text { Cost-Utility } \\
\text { analysis }\end{array}$ & Rituximab & 58307.931 & 7.77 & 0 & & 0 \\
\cline { 2 - 7 } & Natalizumab & 354174.85 & 7.65 & 295866.9249 & -0.124906357 & $\begin{array}{l}\text { abs. } \\
\text { dominated }\end{array}$ \\
\hline
\end{tabular}

\section{One-way Sensitivity Analysis}

According to the tornado diagram in Fig. 3, ICER was most sensitive to the price of Natalizumab and less sensitive to that of Rituximab. In addition, the tornado diagram shows that changes in input parameters had little effect on the result and the ICER rate remained negative.

\section{Probabilistic sensitivity analysis (PSA):}


The results of uncertainty measurement are presented using the cost-effectiveness acceptability curves and ICER scatter plot as follows. The acceptability curves indicated that Rituximab was the most costeffective treatment in $100 \%$ of simulations for the thresholds lower than $\$ 37,641$ (Fig. 4).

The scatter plot showed that Rituximab was totally in the acceptance area below the threshold in $100 \%$ of the cases and defeated Natalizumab, thus being more cost-effective. On the other hand, Natalizumab was in the rejection zone and above the threshold line in $100 \%$ of the cases and was considered as a noncost-effective (inefficient) strategy (Fig. 5).

\section{Discussion}

Along with the identification and approval of new drugs for the management of multiple sclerosis, there has been ever-increasing costs of treating the disease imposed on families and communities (45). Therefore, conducting economic evaluations seems necessary to identify the cheapest, most effective, and thus most cost-effective medicines and suggest them to doctors for prescription. Such studies can also help health policy makers to reduce patients' out-of-pocket payments. To the knowledge of the researchers, this is one of the first health-economic studies conducted to compare Rituximab and NTZ in the treatment of multiple sclerosis. In fact, this is the first study carried out in Iran on the costeffectiveness of Rituximab versus Natalizumab in MS patients.

According to the findings of this study, the mean annual costs of treatment with Natalizumab and Rituximab were $\$ 36,058.08$ and $\$ 5,399.28$, respectively. Thus, the mean cost of a course of treatment per patient was lower with Rituximab than with Natalizumab. One reason for this difference could be the higher price of Natalizumab compared to Rituximab. The studies by Chisari et al. (2021) showed that the annual cost of Rituximab was significantly lower than other approved drugs used in the treatment of MS (20). Hartung (2017) also showed that the annual cost of MS drugs was about $\$ 70,000$ (46), which is consistent with the results of the present study.

The direct medical, direct non-medical, and indirect costs of Natalizumab were $\$ 34,912.80(96.82 \%$ of the total costs), $\$ 665.70$ (1.85\% of the total costs), and $\$ 479.58$ (1.33\% of the total costs), respectively. However, the costs were $4,931.96$ ( $91.34 \%$ of the total costs), 41.12 ( $0.76 \%$ of the total costs), and 426.20 (7.89\% of the total costs) for Rituximab. Direct costs of both drugs accounted for most of the costs, the largest share of which was that of purchasing the main drug ( $94.36 \%$ and $41.33 \%$, respectively). In this regard, the findings of this study are consistent with those of the studies conducted in Iran by Rezaei et al. (2019) (47) and Taheri et al. (2019) (48), and the ones carried out abroad by Dahham et al. (2021) (49), Brodszky et al. (2019) (50), Garcia et al. in Panama (2018) (51), and Ernstsson et al. (2016) (52).

The results of the present research showed that the highest utility rate and the lowest relapse rate in treatment with each drug was found in the patients with an EDSS of 0-2.5, and as disability increased, the life utility rate decreased and the relapse rate increased as well. This might be due to the fact that in higher EDSSs, the disease usually progresses and the patients' limitations increase; so it is natural for the relapse rate to get higher and the utility rate to decrease $(53,54)$. In this respect, the results of this study 
are in line with the ones by Torgauten et al. (2021), Hellgren et al. (2020), Boremalm et al. (2019), and Yamout et al. (2018) (27, 55-57).

Based on the results of the Markov model analysis, the costs of Natalizumab and Rituximab were respectively $\$ 58,307.93$ and $\$ 354,174.86$, and the obtained QALYs were 7.77 and 7.65 over the lifetime horizon. Therefore, since Natalizumab had higher cost and lower QALY, it was considered the recessive option in cost-effectiveness analysis. Thus, Rituximab was more cost effective than Natalizumab.

Rezaei et al. (2019) conducted a study in Iran and examined the cost-utility of Natalizumab versus Fingolimod. They found out that the mean cost per patient during life was $\$ 58,751$ in the Fingolimod arm and the utility was 8.09 QALY, but in the Natalizumab arm, the mean cost and the obtained QALY were $\$ 204,264$ and $\$ 7.37$, respectively. Thus, Natalizumab had higher cost and lower QALY and was the recessive option. This is consistent with the results of the present study (47).

In their study, Taheri et al. (2019) examined the cost-effectiveness of Alemtuzumab versus Natalizumab and concluded that the total discounted costs per patient were $\$ 147,417$ and $\$ 150,579$, respectively. In addition, the mean discounted QALYs were estimated at 7.07 and 6.05 for Alemtuzumab and Natalizumab, respectively, over a period of 20 years. Therefore, Natalizumab was the recessive option, which is consistent with the present study (48).

Walter et al. (2018) also evaluated the cost-utility of Alemtuzumab versus interferon beta, Fingolimod, and Natalizumab for relapsing multiple sclerosis in Austria and found that Alemtuzumab was the dominant option due to having higher total QALY (4.88) and lower total cost ( $€$ 137.409) in comparison with interferon beta-1a ( $€ 200,133$ and QALY of 4.38), Fingolimod ( $€ 240,903$ and QALY of 4.64), and Natalizumab (€ 247.758 and QALY of 4.40). This is in line with the results of the present study (58).

In the study by Hettle et al. (2018) on the cost-effectiveness of Cladribine versus Alemtuzumab and Natalizumab in England, it was found that Cladribine was the dominant strategy over Alemtuzumab and Natalizumab when compared two by two, and quite dominant in the incremental analysis (i.e. they were cheaper and more effective). The total costs and QALYs discounted for Cladribine, Alemtuzumab, and Natalizumab were 92,484 and QALY 9,450, 104,136 and QALY 8,482, and 212,969 and QALY 7,739, respectively, which is consistent with the present study (32).

Montgomery et al. (2017) in the UK examined the cost-effectiveness of Fingolimod and Natalizumab and found that the cost of the former was $£ 334897.93$ and its obtained QALY was 6.18. However, the cost and QALY of the latter were $£ 337501.15$ and 6.35 , respectively. The obtained ICER which was below the threshold in the UK (threshold $\geq 15313.06$ ) showed that Fingolimod was the dominant option, and this is consistent with the present study (59).

The results of the one-way sensitivity analysis indicated that in the cost-utility analysis, the ICER value was negative and the highest sensitivity was to the price of Natalizumab, but considering that in the costutility sensitivity analysis the ICER value remained negative, the results of the study had required 
robustness. In addition, the results of probabilistic sensitivity analysis showed that Rituximab regimen was more cost-effective than Natalizumab and in all cases, it was in the acceptance area and below the threshold. Thus, it had obtained the best results in terms of the mentioned prices. The results also showed that doing sensitivity analysis did not change the status of Rituximab as the most effective drug regimen, suggesting the robust study results. In this regard, the present study is in line with those of Rezaei et al. (2019) and Taheri et al. (2019) in the country, and Walter et al. (2018), Hettle et al. (2018), and Montgomery et al. (2017) abroad $(32,47,48,58,59)$.

One limitation of the present study was the self-reporting of the patients or their companions about direct non-medical and indirect costs, as they were likely to forget or approximate some of the costs. In addition, intangible costs were not calculated in this study due to the inability to measure them accurately

\section{Conclusions}

The results of the present research suggested that Rituximab had higher cost-effectiveness and costutility than Natalizumab. Therefore, considering the results of the sensitivity analysis and the robustness of the results, Rituximab treatment is suggested as the first priority (compared to Natalizumab) to treat the patients with multiple sclerosis, and health policy makers and managers should try to increase insurance coverage and reduce the patients' out-of-pocket payments.

\section{Abbreviations}

MS: Multiple sclerosis, QALY: Quality Adjusted Life Years, EDSS: Expanded Disability Status Scale, DMC: Direct Medical Costs, DNMC: Direct Non-Medical Costs, IC: Indirect Costs, EQ-5D: Euro Quality-5 Dimension, PPP: Purchasing Power Parity, GDP: Gross Domestic Product, PSA: Probabilistic Sensitivity Analysis, WTP: Willingness to Pay

\section{Declarations}

\section{Ethics approval and consent to participate}

All data are collected and handled in accordance with the relevant privacy protection guidelines. According to Iran law, the study did not fall under the remit of the Medical Research Involving Human Subjects Act and no approval by a medical ethics committee was necessary. Verbal consent was obtained from respondents who completed a questionnaire anonymously, and their response expressed their willingness to participate. Written consent was obtained from participants to the cognitive interviews

\section{Consent for publication:}

All participants completed a consent form, stating that they were well-informed about the Content of questionnaires and that they agreed upon the publication of anonymized data. 
Availability of data and material:

The datasets generated and analyzed during the current study are not publicly available because they contain information that could compromise the privacy of research participants, but are available from the corresponding author upon reasonable request.

\section{Competing interests:}

The authors declare no competing interests.

\section{Funding:}

This research did not receive any specific grant from funding agencies in the public, commercial, or notfor-profit sectors.

\section{Authors' contributions:}

M.R: Data curation, Methodology, Software, Roles/Writing - original draft

M.H.M.: Conceptualization, Data curation, Supervision, Validation, Writing - review \& editing M.P.: Conceptualization, Data curation, Methodology, Methodology, Supervision, Validation, Writing review \& editing.

A.R.: Data curation, Methodology, Methodology, Software, Validation, Writing - review \& editing.

Kh.K.: Conceptualization, Data curation, Methodology, Software, Project administration, Investigation, Supervision, Validation, Writing - review \& editing.

\section{Acknowledgements:}

The present article was extracted from the thesis written by Armin Radgoudarzi. The researchers would like to thank the studied patients for their kind cooperation with the researchers in collecting and analyzing data.

\section{References}

1. Oh J, Vidal-Jordana A, Montalban X. Multiple Sclerosis: Clinical Aspects. Curr Opin Neurol. 2018;31:752-9.

2. Lemus HN, Warrington AE, Rodriguez M. Multiple Sclerosis: Mechanisms of Disease and Strategies for Myelin and Axonal Repair. Neurol Clin. 2018;36:1-11.

3. Walton C, King R, Rechtman L, Kaye W, Leray E, Marrie RA, et al. Rising prevalence of multiple sclerosis worldwide: Insights from the Atlas of MS, third edition. Multiple Sclerosis Journal. 2020;26:1816-21. 
4. Solaro C, Gamberini G, Masuccio FG. Depression in Multiple Sclerosis: Epidemiology, Aetiology, Diagnosis and Treatment. CNS drugs. 2018;32:117-33.

5. Almasi-Hashiani A, Sahraian MA, Eskandarieh S. Evidence of an increased prevalence of multiple sclerosis: a population-based study of Tehran registry during 1999-2018. BMC Neurol. 2020;20:169.

6. Izadi S, Nikseresht AR, Poursadeghfard M, Borhanihaghighi A, Heydari ST. Prevalence and Incidence of Multiple Sclerosis in Fars Province, Southern Iran. Iranian journal of medical sciences. 2015;40:390-5.

7. Etemadifar M, Abtahi SH, Akbari M, Murray RT, Ramagopalan SV, Fereidan-Esfahani M. Multiple sclerosis in Isfahan, Iran: an update. Mult Scler. 2014;20:1145-7.

8. Yousefi B, Vahdati SS, Mazouchian H, Hesari RD. Epidemiological Survey of Multiple Sclerosis in East-Azerbaijan Province, Iran, 2014. Intern Med Med Investig J. 2017;2:42-8.

9. Rezaali S, Khalilnezhad A, Moghadasi AN, Chaibakhsh S, Sahraian MA. Epidemiology of multiple sclerosis in Qom: Demographic study in Iran. Ir J neurol. 2013;12:136-43.

10. Mousavizadeh A, Dastoorpoor M, Naimi E, Dohrabpour K. Time-trend analysis and developing a forecasting model for the prevalence of multiple sclerosis in Kohgiluyeh and Boyer-Ahmad Province, southwest of Iran. Public Health. 2018;154:14-23.

11. Eskandarieh S, Molazadeh N, Moghadasi AN, Azimi AR, Sahraian MA. The prevalence, incidence and familial recurrence of multiple sclerosis in Tehran, Iran. Mult Scler Relat Disord. 2018;25:143.

12. Hashemilar M, Ouskui DS, Farhoudi M, Ayromlou H, Asadollahi A. Multiple sclerosis in East Azerbaijan, North West Iran. Neurology Asia. 2011;16:127-31.

13. Etemadifar M, Nikanpour Y, Neshatfar A, Mansourian M, Fitzgerald S. Incidence and prevalence of multiple sclerosis in persian gulf area: A systematic review and meta-analysis. Mult Scler Relat Disord. 2020;40:101959.

14. Wilski M, Tasiemski T. Health-related quality of life in multiple sclerosis: role of cognitive appraisals of self, illness and treatment. Quality of life research: an international journal of quality of life aspects of treatment, care and rehabilitation. 2016;25:1761-70.

15. Youssef C, Barrie U, Elguindy M, Christian Z, Caruso JP, Johnson ZD, et al. Compressive Cervical Myelopathy in Patients With Demyelinating Disease of the Central Nervous System: Improvement After Surgery Despite a Late Diagnosis. Cureus. 2021;13:e13161.

16. da Silva NL, Takemoto MLS, Damasceno A, Fragoso YD, Finkelsztejn A, Becker J, et al. Cost analysis of multiple sclerosis in Brazil: a cross-sectional multicenter study. BMC Health Serv Res. 2016;16:102.

17. Kim Y, Krause TM, Blum P, Freeman L. Disease Modifying Therapies Continue to Drive Up Health Care Cost Among Individuals With Multiple Sclerosis. Mult Scler Relat Disord. 2019;30:69-75.

18. Fernández $\mathrm{O}$, Calleja-Hernández MA, Meca-Lallana J, Oreja-Guevara $\mathrm{C}$, Polanco A, Pérez-Alcántara F. Estimate of the cost of multiple sclerosis in Spain by literature review. Expert Rev Pharmacoecon Outcomes Res. 2017;17:321-33. 
19. Thompson AJ, Baranzini SE, Geurts J, Hemmer B, Ciccarelli O. Multiple Sclerosis. Lancet. 2018;391:1622-36.

20. Chisari CG, Sgarlata E, Arena S, Toscano S, Luca M, Patti F. Rituximab for the treatment of multiple sclerosis: a review. J Neurol. 2021:1-25.

21. Honce JM, Nair KV, Sillau S, Valdez B, Miravalle A, Alvarez E, et al. Rituximab vs placebo induction prior to glatiramer acetate monotherapy in multiple sclerosis. Neurology. 2019;92: e723-e32.

22. Elsisi Z, Hincapie AL, Guo JJ. Expenditure, Utilization, and Cost of Specialty Drugs for Multiple Sclerosis in the US Medicaid Population, 2008-2018. American health \& drug benefits. 2020;13:7484.

23. Xu Y, Mao N, Chirikov V, Du F, Yeh YC, Liu L, et al. Cost-effectiveness of Teriflunomide Compared to Interferon Beta-1b for Relapsing Multiple Sclerosis Patients in China. Clinical drug investigation. 2019;39:331-40.

24. Palmer AJ, van der Mei I, Taylor BV, Clarke PM, Simpson S, Jr., Ahmad H. Modelling the impact of multiple sclerosis on life expectancy, quality-adjusted life years and total lifetime costs: Evidence from Australia. Mult Scler. 2020;26:411-20.

25. Palace J, Bregenzer T, Tremlett $\mathrm{H}$, Oger J, Zhu F, Boggild M, et al. UK multiple sclerosis risk-sharing scheme: a new natural history dataset and an improved Markov model. BMJ open. 2014;4:e004073.

26. Polman $\mathrm{CH}$, O'Connor PW, Havrdova E, Hutchinson M, Kappos L, Miller DH, et al. A randomized, placebo-controlled trial of natalizumab for relapsing multiple sclerosis. $\mathrm{N}$ Engl $\mathrm{J}$ Med. 2006;354:899-910.

27. Yamout BI, El-Ayoubi NK, Nicolas J, Kouzi YE, Khoury SJ, Zeineddine MM. Safety and Efficacy of Rituximab in Multiple Sclerosis: A Retrospective Observational Study. Journal of immunology research. 2018;2018:9084759.

28. Sadovnick AD, Ebers GC, Wilson RW, Paty DW. Life expectancy in patients attending multiple sclerosis clinics. Neurology. 1992;42:991-4.

29. Sun X, Faunce T. Decision-analytical modelling in health-care economic evaluations. The European journal of health economics: HEPAC : health economics in prevention and care. 2008;9:313-23.

30. Abdoli G. Estimation Social Discount Rate For Iran. Economic Research Review. 2009;10:135-56.

31. Haacker M, Hallett TB, Atun R. On discount rates for economic evaluations in global health. Health Policy Plan. 2020;35:107-14.

32. Hettle R, Harty G, Wong SL. Cost-effectiveness of cladribine tablets, alemtuzumab, and natalizumab in the treatment of relapsing-remitting multiple sclerosis with high disease activity in England. $J$ Med Econ. 2018;21:676-86.

33. Pinheiro B, Guerreiro R, Costa J, Miguel LS. Cost-effectiveness of cladribine tablets versus fingolimod in patients with highly active relapsing multiple sclerosis in Portugal. J Med Econ. 2020;23:484-91.

34. Hernandez G, Garin O, Dima AL, Pont A, Martí Pastor M, Alonso J, et al. EuroQol (EQ-5D-5L) Validity in Assessing the Quality of Life in Adults With Asthma: Cross-Sectional Study. Journal of medical 
Internet research. 2019;21:e10178.

35. Goudarzi R, Sari AA, Zeraati H, Rashidian A, Mohammad K, Amini S. Valuation of Quality Weights for EuroQol 5-Dimensional Health States With the Time Trade-Off Method in the Capital of Iran. Value Health Reg Issues. 2019;18:170-5.

36. Rissanen I, Ala-Mursula L, Nerg I, Korhonen M. Adjusted productivity costs of stroke by human capital and friction cost methods: a Northern Finland Birth Cohort 1966 study. The European journal of health economics: HEPAC : health economics in prevention and care. 2021;22:531-45.

37. Latio LSY, Nam NH, Shah J, Smith C, Sakai K, Stonewall Shaban K, et al. Economic burden of the persistent morbidity of nodding syndrome on caregivers in affected households in Northern Uganda. PLoS One. 2020;15:e0238643.

38. Mojahedian MM, Toroski M, Keshavarz K, Aghili M, Zeyghami S, Nikfar S. Estimating the Cost of Illness of Prostate Cancer in Iran. Clin Ther. 2019;41:50-8.

39. World Bank. PPP conversion factor, GDP (LCU per international \$) - Iran, Islamic Rep. [Accessed 5-222020];. Available from: https://data.worldbank.org/indicator/PA.NUS.PPP?locations=IR .

40. Wu X, Xue T, Wang Z, Chen Z, Zhang X, Zhang W, et al. Different Doses of Fingolimod in RelapsingRemitting Multiple Sclerosis: A Systematic Review and Meta-Analysis of Randomized Controlled Trials. Frontiers in pharmacology. 2021;12:621856.

41. Yang T, Tian X, Chen CY, Ma LY, Zhou S, Li M, et al. The efficacy and safety of fingolimod in patients with relapsing multiple sclerosis: A meta-analysis. British journal of clinical pharmacology. 2020;86:637-45.

42. Marseille E, Larson B, Kazi DS, Kahn JG, Rosen S. Thresholds for the cost-effectiveness of interventions: alternative approaches. Bulletin of the World Health Organization. 2015;93:118-24.

43. Iran - GDP per capita. Available from: https://fa.tradingeconomics.com/iran/gdp-per-capita

44. Keshavarz K, Kebriaeezadeh A, Alavian SM, Sari AA, Hemami MR, Lotfi F, et al. A Cost-Utility and Cost-Effectiveness Analysis of Different Oral Antiviral Medications in Patients With HBeAg-Negative Chronic Hepatitis B in Iran: An Economic Microsimulation Decision Model. Hepat Mon. 2016;16:e37435.

45. Moradi G, Safari H, Piroozi B, Qanbari L, Farshadi S, Qasri H, et al. Catastrophic health expenditure among households with members with special diseases: A case study in Kurdistan. Medical journal of the Islamic Republic of Iran. 2017;31:43.

46. Hartung DM. Economics and Cost-Effectiveness of Multiple Sclerosis Therapies in the USA. Neurotherapeutics: the journal of the American Society for Experimental NeuroTherapeutics. 2017;14:1018-26.

47. Rezaee M, Izadi S, Keshavarz K, Borhanihaghighi A, Ravangard R. Fingolimod versus natalizumab in patients with relapsing remitting multiple sclerosis: a cost-effectiveness and cost-utility study in Iran. J Med Econ. 2019;22:297-305.

48. Taheri S, Sahraian MA, Yousefi N. Cost-effectiveness of alemtuzumab and natalizumab for relapsing-remitting multiple sclerosis treatment in Iran: decision analysis based on an indirect 
comparison. J Med Econ. 2019;22:71-84.

49. Dahham J, Rizk R, Kremer I, Evers S, Hiligsmann M. Economic Burden of Multiple Sclerosis in Lowand Middle-Income Countries: A Systematic Review. Pharmacoeconomics. 2021;39:789-807.

50. Brodszky V, Beretzky Z, Baji P, Rencz F, Péntek M, Rotar A, et al. Cost-of-illness studies in nine Central and Eastern European countries. The European journal of health economics: HEPAC : health economics in prevention and care. 2019;20:155-72.

51. Gracia F, Larreategui M, Rodríguez G, Benzadón A, Ortiz M, Morales D, et al. Costs of Multiple Sclerosis in Panama From Societal, Patient Perspectives and Health-Related Quality of Life. PLoS One. 2018;13:e0204681.

52. Ernstsson O, Gyllensten H, Alexanderson K, Tinghög P, Friberg E, Norlund A. Cost of Illness of Multiple Sclerosis - A Systematic Review. PLoS One. 2016;11:e0159129.

53. Nazareth TA, Rava AR, Polyakov JL, Banfe EN, Waltrip li RW, Zerkowski KB, et al. Relapse prevalence, symptoms, and health care engagement: patient insights from the Multiple Sclerosis in America 2017 survey. Mult Scler Relat Disord. 2018;26:219-34.

54. Jones E, Pike J, Marshall T, Ye X. Quantifying the relationship between increased disability and health care resource utilization, quality of life, work productivity, health care costs in patients with multiple sclerosis in the US. BMC Health Serv Res. 2016;16:294.

55. Hellgren J, Risedal A, Källén K. Rituximab in multiple sclerosis at general hospital level. Acta Neurol Scand. 2020;141:491-9.

56. Boremalm M, Juto A, Axelsson M, Novakova L, Frisell T, Svenningsson A, et al. Natalizumab, rituximab and fingolimod as escalation therapy in multiple sclerosis. Eur J Neurol. 2019;26:1060-7.

57. Torgauten HM, Myhr KM, Wergeland S, Bø L, Aarseth JH, Torkildsen Ø. Safety and efficacy of rituximab as first- and second line treatment in multiple sclerosis - A cohort study. Multiple sclerosis journal - experimental, translational and clinical. 2021;7:2055217320973049.

58. Walter E, Berger T, Bajer-Kornek B, Deisenhammer F. Cost-utility analysis of alemtuzumab in comparison with interferon beta, fingolimod, and natalizumab treatment for relapsing-remitting multiple sclerosis in Austria. J Med Econ. 2019;22:226-37.

59. Montgomery SM, Kusel J, Nicholas R, Adlard N. Costs and effectiveness of fingolimod versus alemtuzumab in the treatment of highly active relapsing-remitting multiple sclerosis in the UK: retreatment, discount and disutility. J Med Econ. 2017:1-12.

\section{Figures}




\section{Relapse-Remitting Multiple Sclerosis}

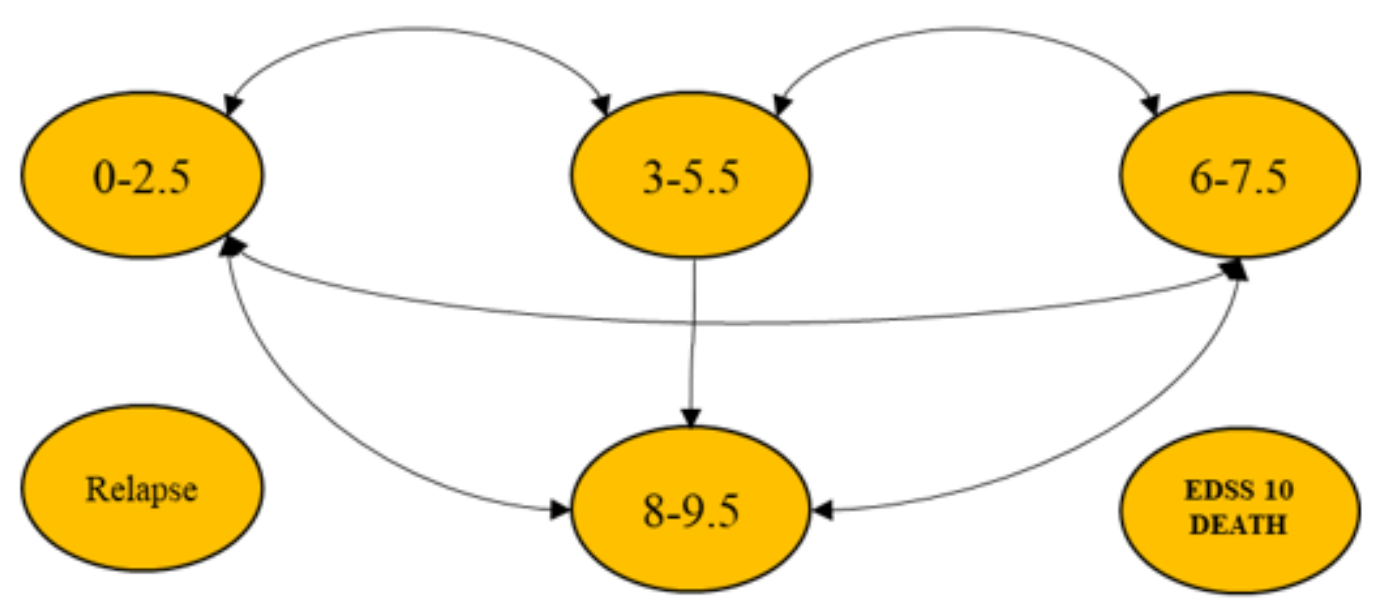

\section{All Patients May Experiences Relapses Or Die}

\section{Figure 1}

Schematic diagram of Markov model for MS (1). 1. Palmer AJ, van der Mei I, Taylor BV, Clarke PM, Simpson S, Jr., Ahmad H. Modelling the impact of multiple sclerosis on life expectancy, quality-adjusted life years and total lifetime costs: Evidence from Australia. Mult Scler. 2020;26:411-20. 


\section{Cost-Effectiveness Analysis}

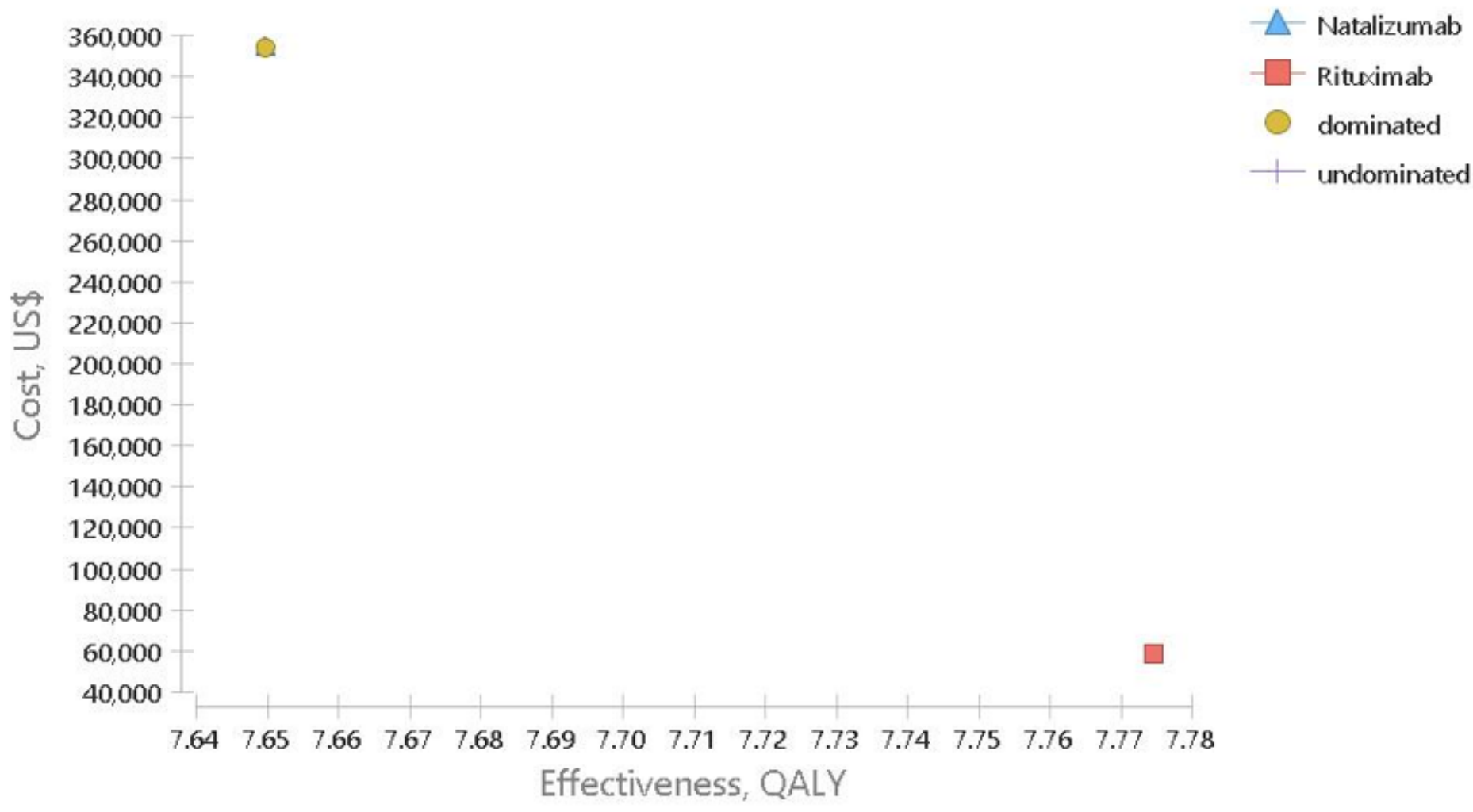

Figure 2

Cost-effectiveness and cost-utility analyses for RRMS patients under treatment with Natalizumab and Rituximab 


\section{Tornado Diagram - Rituximab vs. Natalizumab}

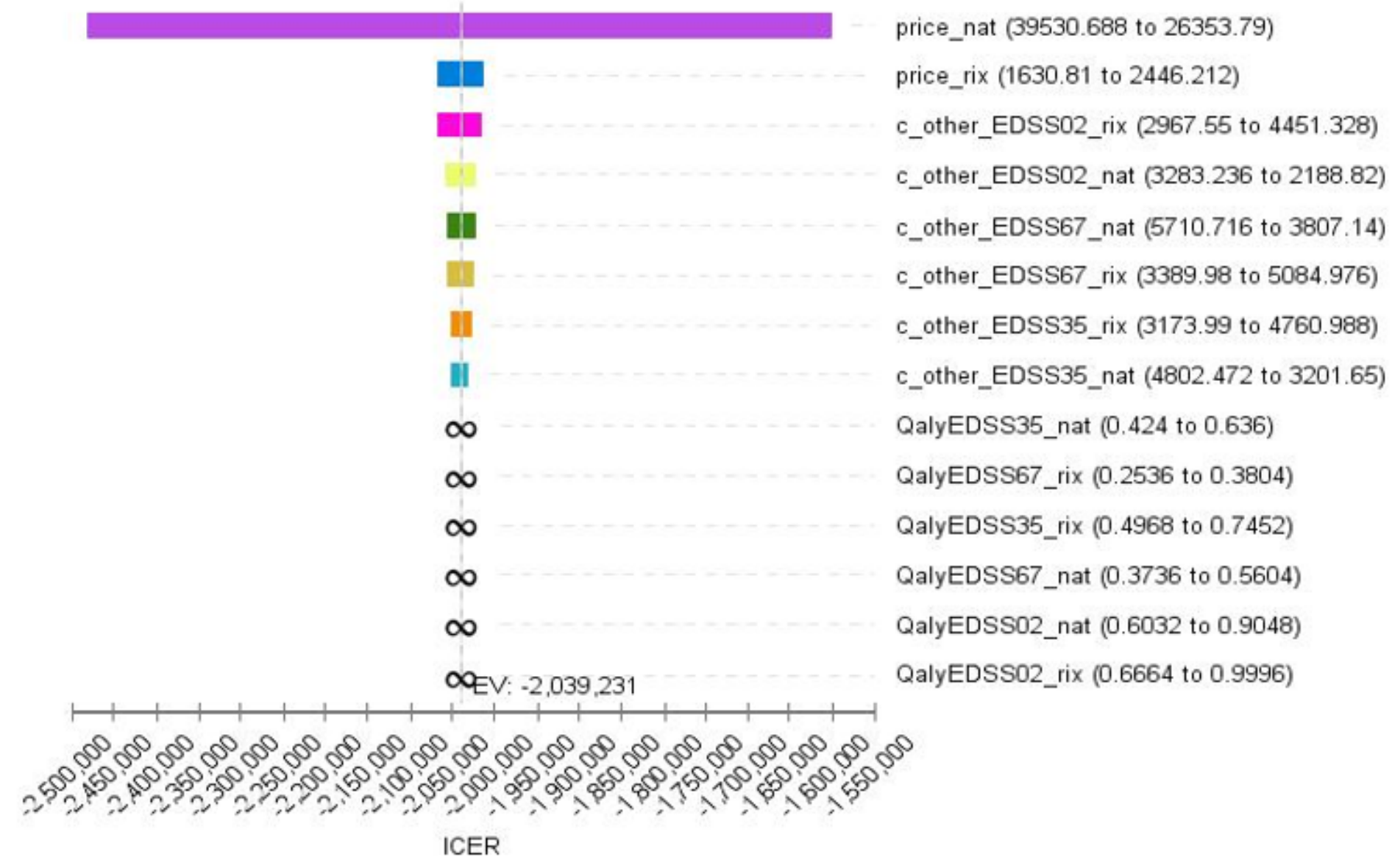

\section{Figure 3}

Tornado diagrams of cost- utility of the studied RRMS patients under treatment with Natalizumab and Rituximab 
CE Acceptability Curve

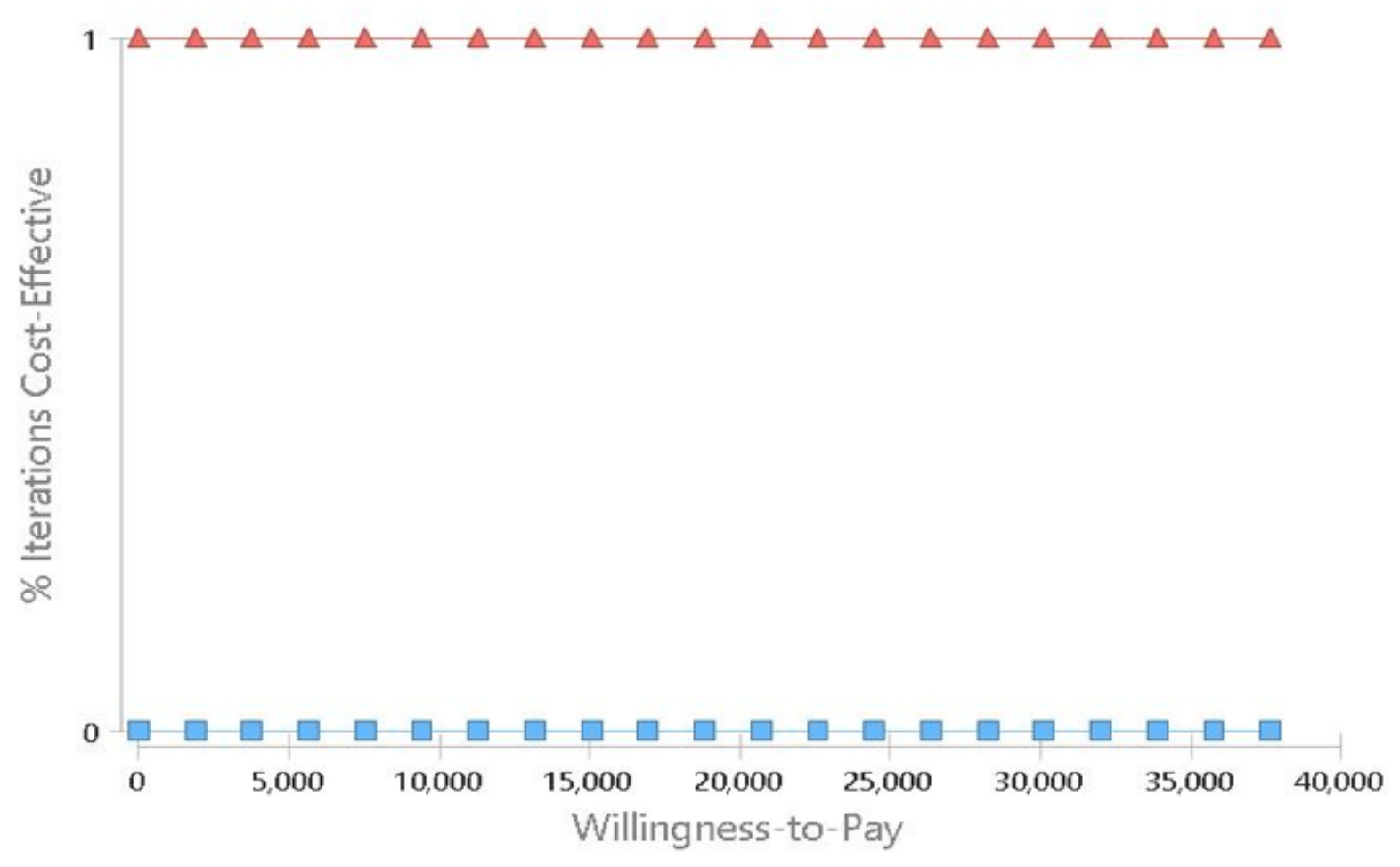

Natalizumab

Rituximab

\section{Figure 4}

The cost-effectiveness acceptability curves of Rituximab versus Natalizumab based on the QALY obtained through the Monte Carlo simulation

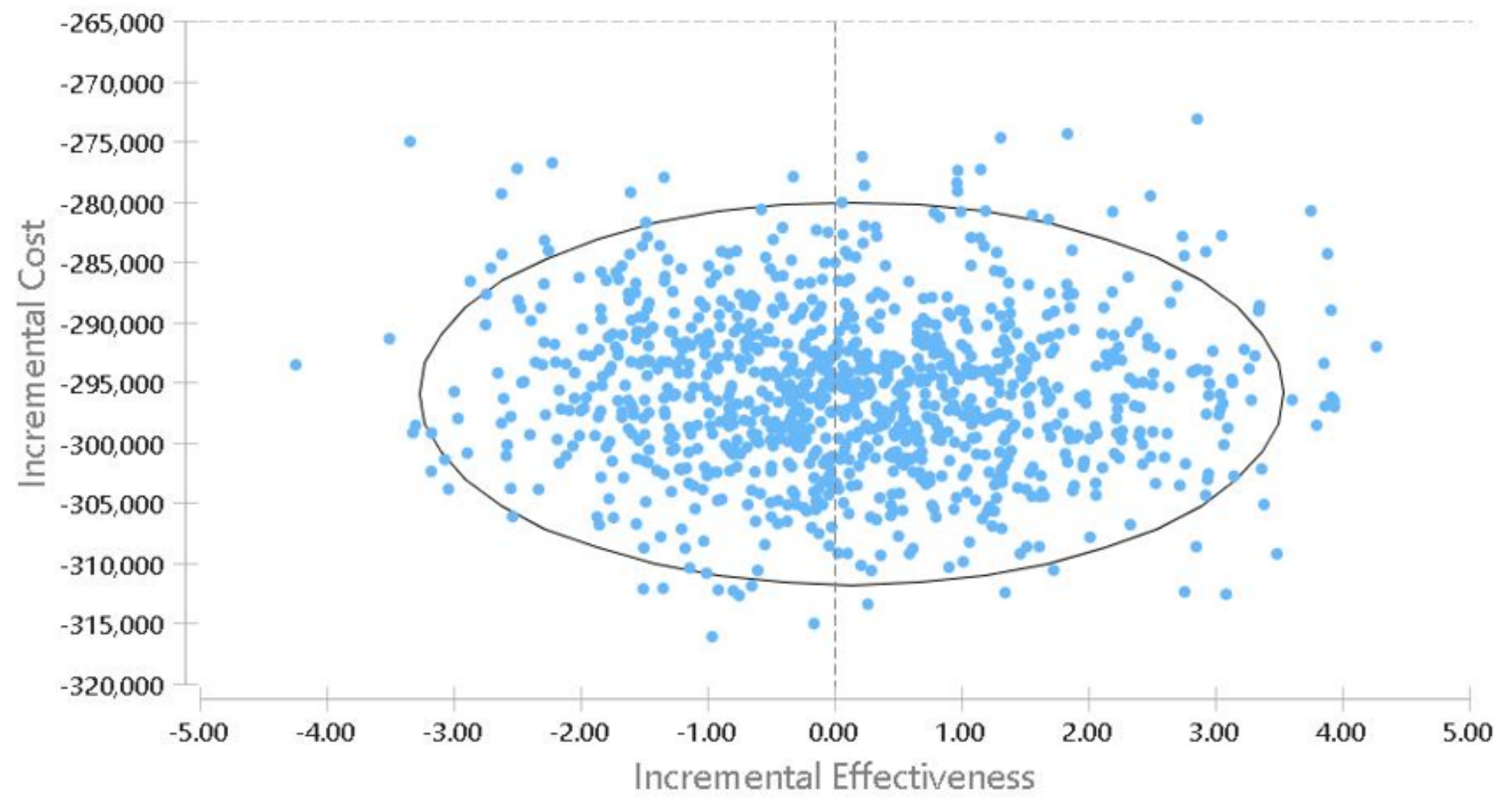


Figure 5

The incremental cost-effectiveness scatter plots of Rituximab versus Natalizumab based on the QALY 